\title{
Genetic signatures of polymorphic microsatellite loci in the Ambiguous silver pomfret, Pampus argenteus (Teleostei, Stromateidae)
}

\author{
Yuan Li', Long-Shan Lin', Tian-Xiang Gao ${ }^{2,3}$ \\ I Third Institute of Oceanography, State Oceanic Administration, Xiamen, Fujian 361005, China 2 Zhejiang \\ Provincial Key Laboratory for Technology Research on Sustainable Utilization of Marine Fishery Resources, \\ Zhoushan, Zhejiang 316021, China 3 National Engineering Research Center for Marine Aquaculture, \\ Zhejiang Ocean University, Zhoushan, Zhejiang 316022, China
}

Corresponding author: Tian-Xiang Gao (gaotianxiang0611@163.com)

Academic editor: Sven Kullander | Received 7 April 2018 | Accepted 2 December 2018 | Published 20 December 2018

http://zoobank.org/43F1B8BC-F6F7-4751-8EC4-F07B72B9257B

Citation: Li Y, Lin L-S, Gao T-X (2018) Genetic signatures of polymorphic microsatellite loci in the Ambiguous silver pomfret, Pampus argenteus (Teleostei, Stromateidae). ZooKeys 810: 139-151. https://doi.org/10.3897/ zookeys.810.25602

\begin{abstract}
Pampus argenteus is a broadly exploited pelagic fish species, commonly misidentified as Pampus echinogaster. Genetic variation and population structure in Pampus argenteus was studied based on seven microsatellite loci. The observed high average allele number, heterozygosity values, and polymorphism information content of $P$. argenteus suggested high genetic diversity. No population genetic differentiation was detected based on the results of pairwise $F_{\text {st }}$, three-dimensional factorial correspondence analysis (3D-FCA) and STRUCTURE analysis, which implied continuous gene flow. Wilcoxon signed rank tests did not indicate significant heterozygosity excess, and recent genetic bottleneck events were not detected. Coupled with previous mitochondrial DNA results, the findings presented here indicate that high gene flow characterizes the current phylogeographic pattern of the species.
\end{abstract}

\section{Keywords}

Genetic diversity, genetic structure, microsatellite DNA, population genetics

Copyright Yuan Li et al. This is an open access article distributed under the terms of the Creative Commons Attribution License (CC BY 4.0), which permits unrestricted use, distribution, and reproduction in any medium, provided the original author and source are credited. 


\section{Introduction}

Species of the genus Pampus Bonaparte, 1834, are mainly distributed in the Indo-West Pacific Ocean and have a rich landing yield in Kuwait, Iran, India, Malaysia, Thailand, China, Korea and Japan (Jia et al. 2004; Divya et al. 2017). Among these species, $P$. argenteus (Euphrasén, 1788) is a broadly exploited pelagic species that has a high economic value because of its highly appreciated taste. Although all species of Pampus are important economical species, the morphological similarity among species of Pampus has resulted in considerable confusion in species-level identification. Pampus argenteus is the most widely distributed species of the genus, and it is usually identified as $P$. echinogaster (Basilewsky, 1855) because of the morphological similarities ( $\mathrm{Li}$ et al. 2013, 2017a). This is mainly a consequence of the absence of critical diagnostic morphological characteristics in the description by Euphrasén (1788), based on only one specimen. Li et al. (2013) collected samples of $P$. argenteus from Kuwait, Pakistan, and China and provided updated and improved morphological diagnosis and DNA barcode data. Li et al. (2017a) proposed diagnostic characteristics of $P$. echinogaster, which is significantly different from $P$. argenteus. Therefore, we speculate that $P$. argenteus is a warm-water species that is widely distributed south of the Taiwan Strait and across Indonesia to the Persian Gulf (Yamada et al. 2009; Li et al. 2013). Pampus punctatissimus (Temminck \& Schlegel, 1845) was regarded as a synonym of $P$. argenteus by some ichthyologists (Bleeker 1852; Haedrich 1984), while a few researchers recognized differences between these species and provided a redescription of $P$. punctatissimus with a detailed morphological comparison with P. argenteus (Liu and Li 1998; Yamada et al. 2009; Nakabo 2013).

Pampus argenteus is a multiple batch spawner with indeterminate fecundity, and spawning starts in mid-May and continues until early October. Transformation from the larval to juvenile stage occurs at 40 days after hatching (Almatar et al. 2000). The eggs, larvae, and adults of this species are all pelagic. Although numerous investigations have been performed on P. argenteus (Meng et al. 2012; Peng et al. 2010a, 2010b; Zhao et al. 2010, 2011; Wu et al. 2012), many reports could actually be for P. echinogaster. Studies on P. argenteus mainly focus on its biology (Kuronuma and Abe 1972), reproductive development (Almatar et al. 2004), and resource investigations (Morgan 1985; Pillai and Menon 2000; Narges et al. 2011; Hashemi et al. 2012; Siyal et al. 2013). To date, few population genetic analyses have been conducted with reliable species identification for this species. Although some reports have described $P$. argenteus from the Atlantic-eastern Pacific (Fowler 1938; Davis and Wheeler 1985; Dulčić et al. 2004; Piper 2010; Sami et al. 2014), far from its center of distribution (the western Pacific and Indian Oceans), such identifications should be analyzed further.

Microsatellites (simple sequence repeats, SSRs) are tandemly repeated motifs of 1-6 bases characterized by a high degree of length polymorphism (Zane et al. 2002), and they are sensitive indicators of population genetic structure (Cheng et al. 2015; Song et al. 2016; Stepien et al. 2017). In previous studies, we evaluated the phylogeographical structure of $P$. argenteus by mitochondrial DNA markers, and two lineages were obtained ( $\mathrm{Li}$ et al. 2017b). To further examine the genetic variation and population structure of $P$. argenteus, seven microsatellite loci were employed in this study, and 
we aim to infer the relative role of biological characteristics and environmental factors involved in shaping the contemporary population genetic structure of this species by combining the results of mitochondrial DNA.

\section{Materials and methods}

\section{Sample collection}

A total of 119 specimens of $P$. argenteus was collected from the coastal waters of Kuwait, Pakistan, and China from 2010 until 2014 (Figure 1, Table 1). All individuals were identified based on morphological characteristics according to Yamada et al. (2009) and Li et al. (2013), and dorsal muscle tissue was excised and preserved in 95\% alcohol.

\section{DNA extraction, amplification and sequencing}

Genomic DNA was isolated from muscle tissue by proteinase $K$ digestion and extracted using the DNeasy Blood and Tissue Kit (Qiagen, Valencia, CA, USA). Seven microsatellite loci developed by Yang et al. (2006) were used in this study (Table 1). Tailed PCR was used to produce fluorescently labeled DNA fragments (Boutin-Ganache et al. 2001). M13R was added to the 5' end of one primer in each pair. An M13 reverse primer that is fluorescently labeled (FAM, HEX, and TAMRA) was included in the PCR, resulting in a labeled product for detection. All loci were conducted separately in a $25 \mu \mathrm{L}$ reaction mixture containing $17.25 \mu \mathrm{L}$ of ultrapure water, $2.5 \mu \mathrm{L}$ of $10 \times \mathrm{PCR}$ buffer (including $\mathrm{MgCl}_{2}$ ), $2 \mu \mathrm{L}$ of dNTPs, $1 \mu \mathrm{L}$ of fluorescently labeled M13R primer and locus specific primer without tail, $1 \mu \mathrm{L}$ of locus specific primer with M13 reverse tail, $0.25 \mu \mathrm{L}$ of Taq polymerase, and $1 \mu \mathrm{L}$ of genomic DNA (10 ng). All loci were initially screened using the following PCR protocol: 5 min at $94^{\circ} \mathrm{C} ; 35$ cycles of $45 \mathrm{~s}$ at $94^{\circ} \mathrm{C}, 45 \mathrm{~s}$ at $50-58^{\circ} \mathrm{C}$, and $45 \mathrm{~s}$ at $72{ }^{\circ} \mathrm{C}$; and a final step of $15 \mathrm{~min}$ at $72^{\circ} \mathrm{C}$. The reactions were then exposed to 72 ${ }^{\circ} \mathrm{C}$ for $45 \mathrm{~min}$ and held at $4{ }^{\circ} \mathrm{C}$ until further analysis. PCR products were diluted 20 fold with ultrapure Milli-Q water before being further diluted ( 1 in 5 ) in formamide containing the LIZ-500 size standard. The samples were separated by capillary gel-electrophoresis on an ABI 3730xl automated sequencer (Applied Biosystems). To score the consistency of microsatellite fragments, nearly $20 \%$ of PCR products were restored for replication (Williams et al. 2015). Microsatellite loci genotyping from six populations were determined in GENEMARKER version 2.2.0 software (SoftGenetics, State College, PA, USA).

\section{Data analysis}

The number of alleles $\left(N_{A}\right)$, observed heterozygosity $\left(H_{O}\right)$ and expected heterozygosity $\left(H_{E}\right)$ were estimated using POPGENE 1.32 (Yeh et al. 1999). The polymorphism information content (PIC) was calculated using the Microsoft Excel Microsatellite Toolkit 


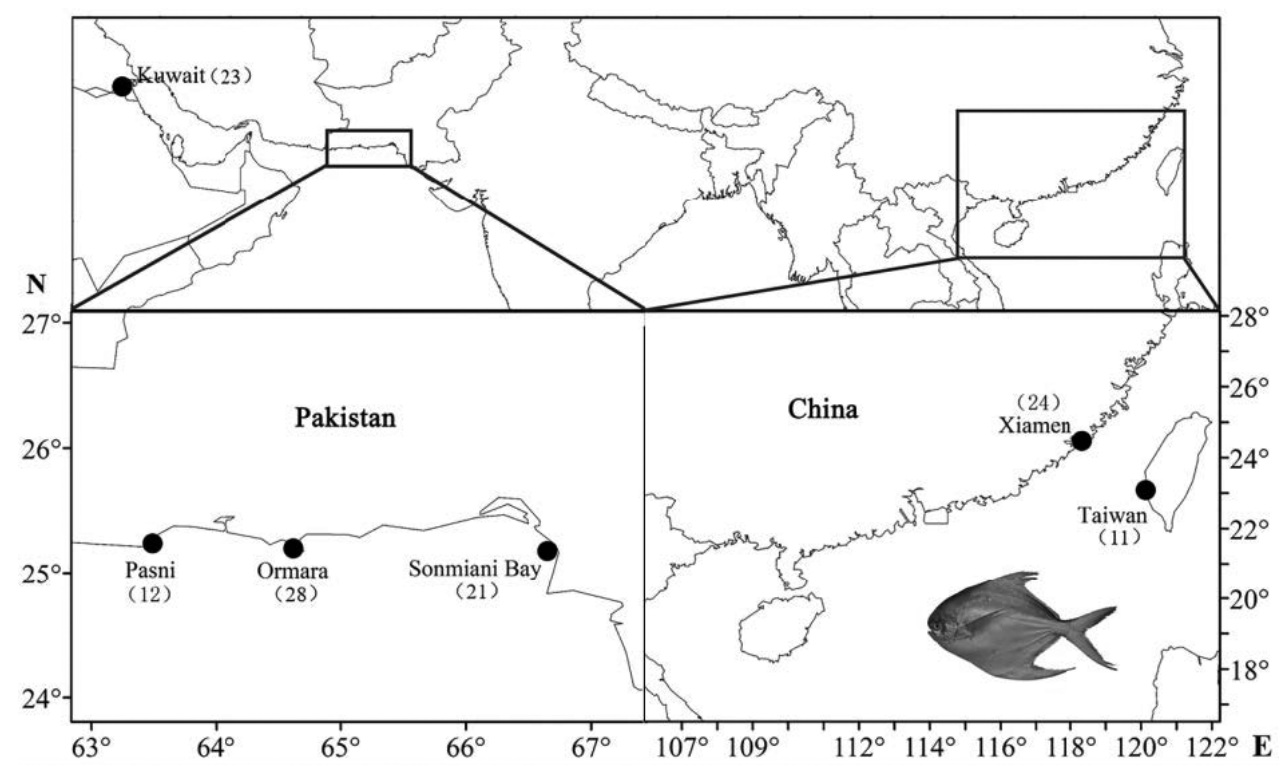

Figure I. Locations (black circle) for sample collection of $P$. argenteus.

(Botstein et al. 1980; Raymond and Rousset 1995). GENEPOP 3.4 was used to test deviations from the Hardy-Weinberg equilibrium (HWE) and the linkage disequilibrium of each locus (Raymond and Rousset 1995). The presence of null alleles and potential scoring errors were addressed using MICRO-CHECKER 2.2.3 (Van Oosterhout et al. 2004).

FSTAT 2.9.3 (Goudent 2001) was used to calculate the allelic richness $\left(R_{\mathrm{S}}\right)$ value and assess the $F_{\text {st }}$ values. The 3D-FCA (three-dimensional factorial correspondence analysis) was performed in Genetix version 4.05 (Belkir et al. 2004) by making no a priori assumptions about the population groupings. The $(\delta \mu)^{2}$ genetic distance was obtained by POPULATIONS 1.2 (Lespinet et al. 2002), and the UPGMA tree was drawn by Treeview (Page 1996).

The possibility of a cryptic population structure of $P$. argenteus was checked using STRUCTURE (Pritchard et al. 2000). Population groups were simulated from $K=1$ to 6, with each $K$ run 10 independent times. Possible mixed ancestry and correlated allele frequencies were assumed, and 1,000,000 Markov chain Monte Carlo (MCMC) steps were used, with the first 100,000 steps discarded as burn-in. To estimate the most likely number of clusters $(K)$, an ad hoc approach (Pritchard et al. 2000) was performed by obtaining the mean posterior probability of the data $\Delta K$ and analyzing the dataset for $K=2$, where the value did not increase, peak or plateau, as expected ( $\mathrm{Li}$ and Liu 2018).

The Bottleneck 1.2.02 program (Piry et al. 1999) was implemented to detect evidence of recent bottleneck events under three mutation models, the infinite allele model (IAM), stepwise mutation model (SMM) and two-phase mutation model (TPM), where $95 \%$ single-step mutations and 5\% multiple steps mutations with 1000 simulation iterations were set as recommended (Zeng et al. 2012). We also provide a graphical descriptor of the shape about the allele frequency distribution (mode-shift indicator) that differentiates bottlenecked and stable populations (Luikart et al. 1998). 
Table I. Summary statistics for the variability seven polymorphic microsatellite loci in six $P$. argenteus populations.

\begin{tabular}{|c|c|c|c|c|c|c|c|c|c|c|c|}
\hline \multirow[t]{2}{*}{ Location } & \multirow{2}{*}{$\begin{array}{l}\text { Number of } \\
\text { individuals }\end{array}$} & \multirow[t]{2}{*}{ Date } & \multicolumn{8}{|c|}{ Locus } & \multirow[t]{2}{*}{ Average } \\
\hline & & & Parameters & Par 03 & Par 08 & Par 20 & Par 05 & Par 12 & Par 18 & Par 17 & \\
\hline Sonmiani & 21 & 2010.12 & $A$ & 19 & 12 & 10 & 10 & 15 & 10 & 13 & 12.71 \\
\hline \multirow[t]{4}{*}{ Bay (SO) } & & & $R_{S}$ & 13.360 & 10.000 & 6.041 & 5.478 & 9.412 & 5.634 & 10.618 & 8.649 \\
\hline & & & $H_{O}$ & 0.429 & 0.750 & 0.810 & 0.476 & 0.600 & 0.600 & 0.789 & 0.636 \\
\hline & & & $H_{E}$ & 0.948 & 0.923 & 0.855 & 0.837 & 0.917 & 0.844 & 0.930 & 0.893 \\
\hline & & & PIC & 0.920 & 0.892 & 0.815 & 0.798 & 0.885 & 0.800 & 0.898 & 0.858 \\
\hline Ormara & 28 & 2010.12 & $A$ & 18 & 15 & 12 & 15 & 16 & 15 & 16 & 15.29 \\
\hline \multirow[t]{4}{*}{$(\mathrm{OR})$} & & & $R_{S}$ & 11.130 & 7.396 & 8.522 & 10.453 & 10.721 & 7.649 & 10.962 & 9.548 \\
\hline & & & $H_{O}$ & 0.333 & 0.679 & 0.786 & 0.857 & 0.889 & 0.464 & 0.778 & 0.684 \\
\hline & & & $H_{E}$ & 0.927 & 0.881 & 0.899 & 0.921 & 0.924 & 0.885 & 0.926 & 0.909 \\
\hline & & & PIC & 0.904 & 0.852 & 0.872 & 0.897 & 0.899 & 0.856 & 0.902 & 0.883 \\
\hline \multirow[t]{5}{*}{ Pasni (PS) } & 12 & 2010.12 & $A$ & 11 & 9 & 8 & 10 & 14 & 9 & 13 & 10.57 \\
\hline & & & $R_{S}$ & 9.000 & 5.647 & 5.647 & 6.400 & 12.522 & 6.698 & 8.471 & 7.769 \\
\hline & & & $H_{O}$ & 0.250 & 0.667 & 1.000 & 0.750 & 0.833 & 0.333 & 0.667 & 0.643 \\
\hline & & & $H_{E}$ & 0.928 & 0.859 & 0.859 & 0.880 & 0.960 & 0.888 & 0.920 & 0.899 \\
\hline & & & PIC & 0.879 & 0.805 & 0.800 & 0.828 & 0.914 & 0.833 & 0.871 & 0.847 \\
\hline Kuwait & 23 & 2011.09 & $A$ & 20 & 10 & 11 & 13 & 14 & 15 & 13 & 13.71 \\
\hline \multirow[t]{4}{*}{$(\mathrm{KW})$} & & & $R_{S}$ & 13.444 & 3.421 & 6.782 & 6.541 & 9.584 & 8.015 & 8.015 & 7.972 \\
\hline & & & $H_{O}$ & 0.727 & 0.455 & 0.957 & 0.636 & 0.773 & 0.478 & 0.565 & 0.656 \\
\hline & & & $H_{E}$ & 0.947 & 0.724 & 0.871 & 0.867 & 0.916 & 0.895 & 0.895 & 0.874 \\
\hline & & & PIC & 0.921 & 0.685 & 0.838 & 0.834 & 0.887 & 0.864 & 0.864 & 0.842 \\
\hline Taiwan & 11 & 2012.09 & $A$ & 14 & 10 & 7 & 11 & 8 & 9 & 11 & 10.00 \\
\hline \multirow[t]{4}{*}{ (TW) } & & & $R_{S}$ & 12.500 & 5.500 & 4.172 & 9.680 & 7.118 & 7.333 & 7.118 & 7.632 \\
\hline & & & $H_{O}$ & 0.500 & 0.727 & 0.636 & 0.727 & 0.455 & 0.545 & 0.545 & 0.591 \\
\hline & & & $H_{E}$ & 0.968 & 0.857 & 0.797 & 0.939 & 0.900 & 0.905 & 0.900 & 0.895 \\
\hline & & & PIC & 0.914 & 0.798 & 0.732 & 0.887 & 0.843 & 0.848 & 0.845 & 0.838 \\
\hline Xiamen & 24 & 2014.04 & $A$ & 20 & 16 & 13 & 11 & 16 & 11 & 15 & 14.57 \\
\hline \multirow[t]{4}{*}{$(\mathrm{XM})$} & & & $R_{S}$ & 15.781 & 11.755 & 8.229 & 6.227 & 8.417 & 5.409 & 9.600 & 9.345 \\
\hline & & & $H_{O}$ & 0.417 & 0.875 & 0.750 & 0.708 & 0.682 & 0.667 & 0.708 & 0.687 \\
\hline & & & $H_{E}$ & 0.957 & 0.934 & 0.897 & 0.857 & 0.902 & 0.832 & 0.915 & 0.899 \\
\hline & & & PIC & 0.933 & 0.909 & 0.868 & 0.820 & 0.872 & 0.793 & 0.887 & 0.869 \\
\hline
\end{tabular}

Abbreviations: $A$ : allelic number, $R_{S}$ : allelic richness, $H_{O}$ : observed heterozygosity, $H_{E}$ : expected heterozygosity, PIC: polymorphism information content.

\section{Results}

A total of 150 alleles were detected by seven microsatellite loci for six populations, with a range of 14 (Par 20) to 31 (Par 03) (Table 1). The $N_{A}, H o, H_{E}$, and PIC of P. argenteus are shown in Table 1 . All the PIC values were greater than 0.5 , which suggested the high genetic diversity of this species (PIC $>0.5$ ) (Table 1). Two microsatellite loci (Par 03 and Par 05) showed deviations from the Hardy-Weinberg equilibrium in all six populations, and null alleles for these loci were also detected for these two loci. Linkage disequilibrium was not detected between pairs of loci for all populations.

The values of pairwise $F_{\text {st }}$ showed low genetic differentiation among $P$. argenteus populations ranging from 0.001 to 0.026 . Most $P$-values were not significant after sequential Bonferroni procedures except those between Kuwait $(\mathrm{KW})$ and the other populations (Xiamen and Sonmiani Bay) (Table 2). The $(\delta \mu)^{2}$ genetic distance was obtained according to the allele frequency by POPULATION software, and the UPGMA tree was constructed by this method (Table 2). The topology of the UP- 
Table 2. Pairwise $F_{\text {st }}$ (below diagonal) and $(\delta \mu)^{2}$ genetic distance (above diagonal) among $P$. argenteus populations.

\begin{tabular}{lcccccc}
\hline & SO & OR & PS & KW & TW & XM \\
\hline SO & & 1.873 & 1.026 & 1.267 & 1.974 & 0.815 \\
OR & 0.005 & & 1.617 & 1.064 & 1.530 & 2.487 \\
PS & 0.002 & -0.002 & & 0.909 & 0.505 & 0.463 \\
KW & $0.026^{*}$ & 0.019 & 0.018 & & 1.301 & 1.980 \\
TW & -0.003 & 0.003 & 0.001 & 0.029 & & 1.029 \\
XM & 0.004 & 0.006 & 0.001 & $0.022^{*}$ & 0.010 & \\
\hline
\end{tabular}

*indicate $P<0.05$. Abbreviations: SO: Sonmiani Bay, OR: Ormara, PS: Pasni, KW: Kuwait, TW: Taiwan, XM: Xiamen.

Figure 2. The UPGMA tree based on $(\delta \mu)^{2}$ genetic distance of six $P$. argenteus populations. Abbreviations: SO: Sonmiani Bay, OR: Ormara, PS: Pasni, KW: Kuwait, TW: Taiwan, XM: Xiamen.

GMA tree showed that $P$. argenteus populations from China, Pakistan and Kuwait coastal waters clustered together and did not relate to their geographical distributions (Figure 2).

According to the results of the 3D-FCA, the first, second and third principal components can explain $25.91 \%, 23.08 \%$, and $17.92 \%$ of the overall variation, respectively (Figure 3). Individuals from population Kuwait (KW) and Taiwan (TW) showed a rather distant genetic relationship with the other four populations.

The Bayesian cluster analysis showed that the model with $K=2$ resulted in the highest $\Delta K$ value (Figure 4 ). A total of $70.8 \%$ of the sampled individuals from KW were assigned to the second cluster, while five others exhibited lower assignment probabilities to the second cluster (43.2-58.1\%). Obvious differences of proportion in the two inferred clusters were not detected in the five other populations (Table 3).

The population demography analysis showed no significant heterozygosity excess observed under all three mutation models by the Wilcoxon sign-rank test $(P>0.05)$, which suggested that $P$. argenteus should be in mutation-drift equilibrium (Table 4). Additionally, a normal L-shaped allele frequency distribution ('mode-shift' indicator) was detected for all six populations, suggesting population stability. 


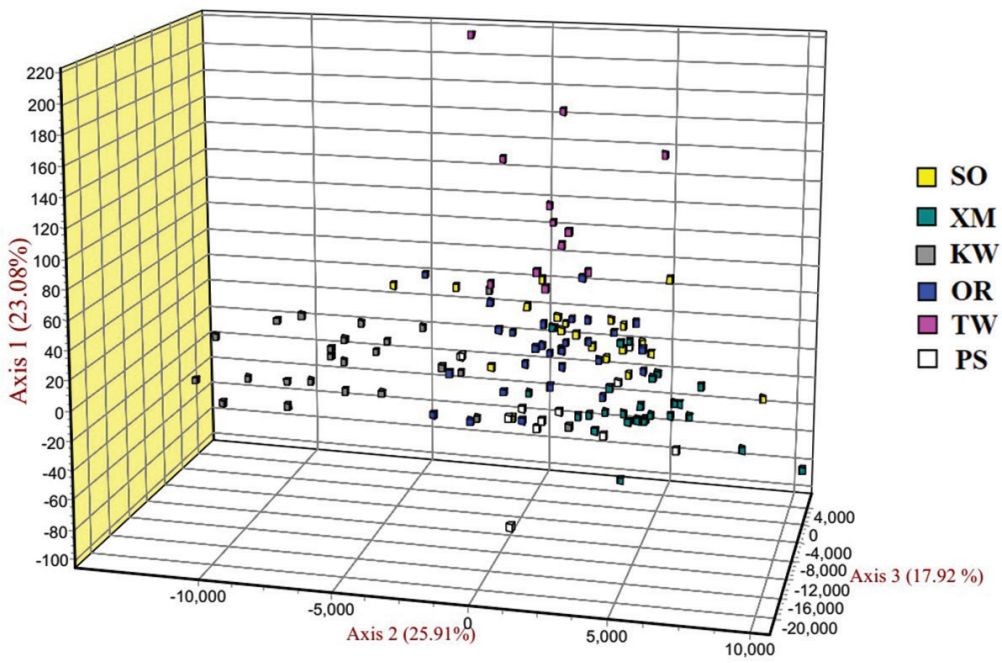

Figure 3. 3D-FCA showing relationships among six populations of $P$. argenteus based on seven microsatellite loci. Abbreviations: SO: Sonmiani Bay, OR: Ormara, PS: Pasni, KW: Kuwait, TW: Taiwan, XM: Xiamen.
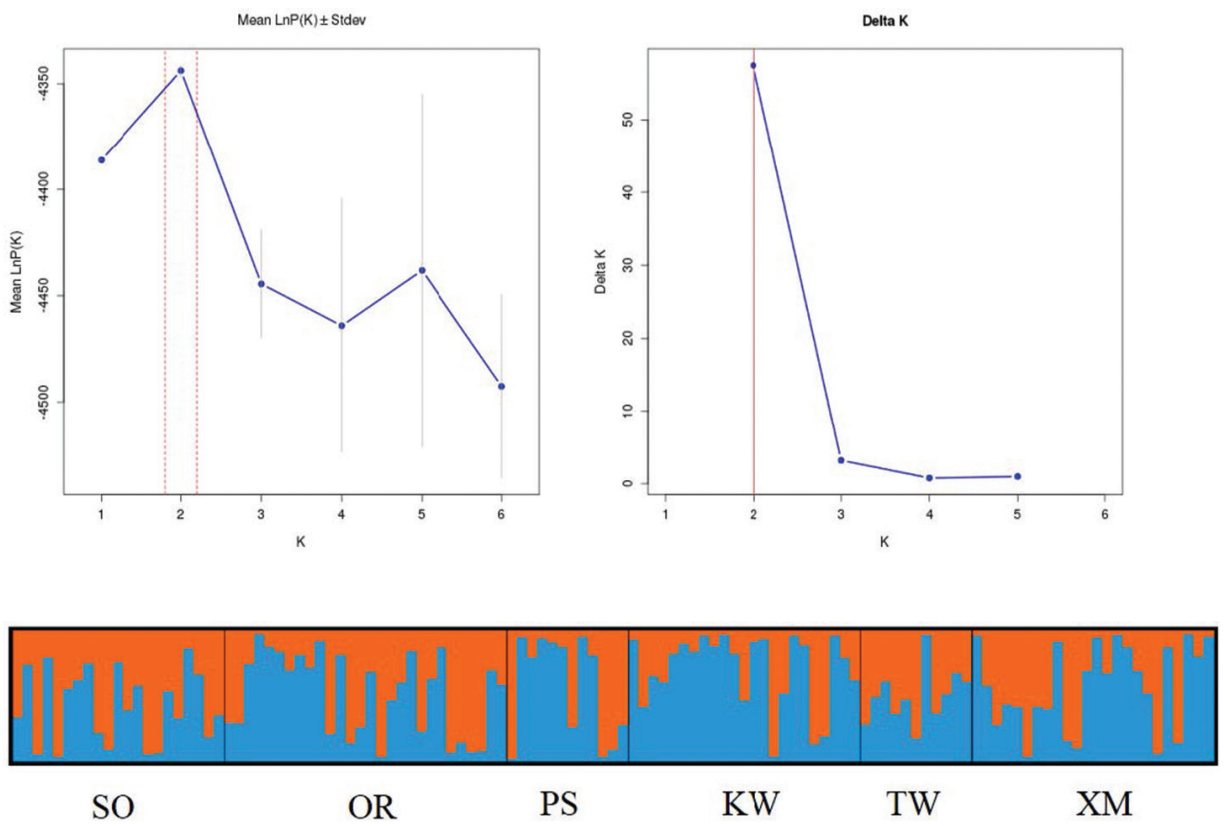

Figure 4. Results of the STRUCTURE analysis from seven microsatellite loci in $P$. argenteus $(K=2)$. Vertical lines are proportional to the probability of individual membership in the simulated cluster. Abbreviations: SO: Sonmiani Bay, OR: Ormara, PS: Pasni, KW: Kuwait, TW: Taiwan, XM: Xiamen. 
Table 3. Proportion of six $P$. argenteus populations in each of the two inferred clusters.

\begin{tabular}{|c|c|c|c|}
\hline \multirow{2}{*}{ Populations } & \multicolumn{2}{|c|}{ Inferred clusters } & \multirow[b]{2}{*}{ Number of individuals } \\
\hline & 1 & 2 & \\
\hline SO & 0.568 & 0.432 & 21 \\
\hline OR & 0.474 & 0.526 & 28 \\
\hline PS & 0.419 & 0.581 & 12 \\
\hline KW & 0.292 & 0.708 & 23 \\
\hline TW & 0.494 & 0.506 & 11 \\
\hline $\mathrm{XM}$ & 0.420 & 0.580 & 24 \\
\hline
\end{tabular}

Abbreviatiosn: SO: Sonmiani Bay, OR: Ormara, PS: Pasni, KW: Kuwait, TW: Taiwan, XM: Xiamen.

Table 4. Results of Wilcoxon's heterozygosity excess test, Mode shift indicator for a genetic bottleneck in six $P$. argenteus populations.

\begin{tabular}{lcccc}
\hline \multirow{2}{*}{ Populations } & \multicolumn{3}{c}{ Wilcoxon sign-rank test } & \multirow{2}{*}{ Mode shift } \\
\cline { 2 - 4 } & IAM & TPM & SMM & L \\
SO & 0.004 & 0.469 & 0.531 & L \\
OR & 0.004 & 0.531 & 0.711 & L \\
PS & 0.008 & 0.234 & 0.469 & L \\
KW & 0.148 & 0.961 & 0.996 & L \\
TW & 0.020 & 0.289 & 0.289 & L \\
XM & 0.004 & 0.004 & 0.945 & \\
\hline
\end{tabular}

Abbreviations: SO: Sonmiani Bay, OR: Ormara, PS: Pasni, KW: Kuwait, TW: Taiwan, XM: Xiamen.

\section{Discussion}

The degree of genetic variation is particularly important for the sustainability and evolution of species, and the strong correlation between genetic diversity and overall fitness has been reported (Reed and Frankham 2003; Vandewoestijne et al. 2008). Population genetic analyses could provide important insights on the genetic diversity of species and have directly informed fishery managers about the appropriate units of management (Ovenden et al. 2010; Dudgeon et al. 2012). Microsatellites are characterized by a high degree of length polymorphism (Zane et al. 2002), and they represent one of the most popular molecular markers in population genetic studies (Carlsson et al. 2004; Cheng et al. 2015). In this study, high average $N_{A}$, heterozygosity values and PIC of $P$. argenteus were detected by seven microsatellite loci, which is consistent with the mitochondrial DNA results of previous studies (Li et al. 2017b). High genetic diversity by mitochondrial DNA and microsatellite DNA may be related to a large effective population size, the immigration of new genes by the intermixing of different populations and/or low selection pressure. Although many marine organisms have been subjected to overfishing, Pampus argenteus presents a considerable yield, indicating a large population size. The wide distribution range of habitats indicates that $P$. argenteus faces limited natural selection pressure and can accumulate greater genetic variation. Significant excess $H_{O}$ was not observed, which showed that $P$. argenteus has 
not experienced bottleneck effect events. Moreover, the selection of loci with high PIC for the analysis can also lead to high genetic diversity.

Microsatellite markers have demonstrated to be highly sensitive for detecting the population structure of fish (Cheng et al. 2015; Stepien et al. 2017; Li et al. 2018). In this study, analyses based on seven microsatellite loci revealed low levels of genetic differentiation for $P$. argenteus. The Bayesian clustering analysis by STRUCTURE also suggested that the distribution proportions of two inferred clusters were not very different from each other. Similar level of genetic differentiation was detected in mitochondrial DNA (Li et al. 2017b). Marine fish populations usually show fluent gene flow and low levels of genetic differentiation because of their high dispersal potential of different life-history stages coupled with an absence of physical barriers to movement (Beheregaray and Sunnucks 2001). Physical distance has frequently been considered the main factor for isolation (Palumbi 1994). However, although long geographic distances occurred among the three countries, the expected genetic differentiation was not detected. Marine currents may play an important role in shaping the contemporary phylogeographic pattern of marine fishes (Xie and Watanabe 2007). For example, the eggs, larvae, or active adults of Trachurus japonicus can be transported over a long distance by the Kuroshio Current along the shelf slope of the East China Sea from areas northeast of Taiwan to the coastal waters of Japan (Cheng et al. 2015). The migratory behavior of $P$. argenteus during its entire life stage could increase the gene flow and weaken the genetic differentiation among geographic populations (Beheregaray and Sunnucks 2001).

In conclusion, high genetic homogeneity among six $P$. argenteus populations was detected, and the contemporary genetic structure of the species revealed in this study can preliminarily improve the genetic knowledge and provide a firm basis to guide fishery stock management in the Indo-Pacific Ocean. Unfortunately, only six geographical populations of $P$. argenteus were collected, which is not sufficient for an even sampling throughout its entire distribution in the Indo-Pacific Ocean. To describe the phylogeographic pattern of $P$. argenteus, additional representative populations should be collected for further analysis.

\section{Acknowledgments}

The present study could not have been performed without assistance from Dr Pengfei Li, Dr Fozia Khan Siyal, and Professor Weizhong Chen during the collection of $P$. argenteus specimens. We sincerely thank the reviewers and subject editor, whose comments greatly improved the manuscript. The work was supported by the National Natural Science Foundation of China (41776171), the International Science \& Technology Cooperation Program of China (2015DFR30450), the National Programme on Global Change and Air-Sea Interaction (GASI-02-SCS-YSWspr/aut), and the Scientific Research Foundation of Third Institute of Oceanography, SOA (2016010). All authors declare that we have no conflict of interest. 


\section{References}

Almatar SM, Lone KP, Abu-Rezq TS, Yousef AA (2004) Spawning frequency, fecundity, egg weight and spawning type of silver pomfret, Pampus argenteus (Euphrasen) (Stromateidae), in Kuwait waters. Journal of Applied Ichthyology 20: 176-188. https://doi.org/10.1111/ j.1439-0426.2004.00546.x

Almatar S, Elah AA, Abu-Rezq T (2000) Larval developmental stages of laboratory-reared silver pomfret, Pampus argenteus. Ichthyological Research 47: 137-141. https://doi.org/10.1007/ BF02684233

Beheregaray LB, Sunnucks P (2001) Fine-scale genetic structure, estuarine colonization and incipient speciation in the marine silverside fish Odontesthes argentinensis. Molecular Ecology 10: 2849-2866. https://doi.org/10.1046/j.1365-294X.2001.t01-1-01406.x

Belkir K, Borsa P, Chikhi L, Raufaste N, Bonhomme F (2004) GENETIX 4.05, logiciel sous Windows TM pour la génétique des populations. Laboratoire Génome, Populations, Interactions, Université de Montpellier II: Montpellier.

Bleeker P (1852) Bijdrage tot de kennis der Makreelachtige visschen van den Soenda-Molukschen Archipel. Bataviaasch Genootschap van Kunsten en Wetenschappen, 1-93.

Botstein D, White RL, Skolnick M, Davis RW (1980) Construction of a genetic linkage map in man using restriction fragment length polymorphisms. American Journal of Human Genetics 32: 314-331.

Boutin-Ganache I, Raposo M, Raymond M, Deschepper CF (2001) M13-tailed primers improve the readability and usability of microsatellite analysis performed with two different allele-sizing methods. Biotechniques 31: 24-28. https://doi.org/10.2144/01311bm02

Carlsson J, McDowell JR, Diaz-Jaimes P, Carlsson JE, Bole SB, Gold JR, et al. (2004) Microsatellite and mitochondrial DNA analyses of Atlantic bluefin tuna (Thunnus thynnus thynnus) population structure in the Mediterranean Sea. Molecular Ecology 13: 3345-3356. https://doi.org/10.1111/j.1365-294X.2004.02336.x

Cheng J, Yanagimoto T, Song N, Gao T (2015) Population genetic structure of chub mackerel Scomber japonicus in the Northwestern Pacific inferred from microsatellite analysis. Molecular Biology Reports 42: 37-382. https://doi.org/10.1007/s11033-014-3777-2

Davis P, Wheeler A (1985) The occurrence of Pampus argenteus (Euphrasen, 1788), (Osteichthyes, Perciformes, Stromateoidei, Stromateidae) in the North Sea. Journal of Fish Biology 26: 105-109. https://doi.org/10.1111/j.1095-8649.1985.tb04247.x

Divya PR, Mohitha C, Rahul GK, Shanis CPR, Basheer VS, Gopalakrishnan A (2017) Molecular based phylogenetic species recognition in the genus Pampus (Perciformes: Stromateidae) reveals hidden diversity in the Indian Ocean. Molecular Phylogenetics and Evolution 109: 240-245. https://doi.org/10.1016/j.ympev.2016.12.030

Dudgeon CL, Blower DC, Broderick D, Giles JL, Holmes BJ, Kashiwagi T, Krück NC, Morgan JAT, Tillett BJ, Ovenden JR (2012) A review of the application of molecular genetics for fisheries management and conservation of sharks and rays. Journal of Fish Biology 80: 1789-1843. https://doi.org/10.1111/j.1095-8649.2012.03265.x

Dulčić J, Jardas I, Pallaoro A, Lipeg L (2004) On the validity of the record of silver pomfret Pampus argenteus (Stromateidae) from the Adriatic Sea. Cybium 28: 69-71. 
Euphrasén BA (1788) Beskrifning på 3:ne fiskar. Kongliga Vetenskaps-Academiens Handlingar 9: $51-55$.

Fowler HW (1938) The fishes of the George Vanderbilt South Pacific Expedition 1937. Monographs of the Academy of Natural Sciences of Philadelphia 2: 1-349.

Goudent J (2001) FSTAT, Version 2.9.3: a program to estimate and test gene diversities and fixation indices. http://www.unil.ch/izea/softwares/fstat.html

Hashemi SAR, Safikhani H, Vahabnezhad A (2012) Growth, mortality parameters and exploitation rate of silver pomfret (Pampus argenteus Euphrasen, 1788) in Northwest of Persian Gulf (Khuzestan Coastal Waters, Iran). American Eurasian Journal of Agricultural and Environmental Sciences 12: 1095-1101. https://doi.org/10.5829/idosi.aejaes.2012.12.08.66127

Haedrich RL (1984) Stromateidae. In: Fischer W, Bianchi G (Eds) FAO Species Identification Sheets for Fishery Purposes. Western Indian Ocean (Fishing Area 51). Vol. 4. FAO, Rome.

Jia X, Li Y, Li C, Qiu Y, Gan J (2004) Environment and Fishery Resources in the Exclusive Economic Zone and the Continental Shelf of South China Sea. Science Press, Beijing, $378-380$.

Kuronuma K, Abe Y (1972) Fish of Kuwait. Kuwait Institute of Scientific Research: University of California Press.

Lespinet O, Wolf YI, Koonin EV, Aravind L (2002) The role of lineage-specific gene family expansion in the evolution of eukaryotes. Genome Research 12: 1048-1059. https://doi. org/10.1101/gr.174302

Li Y, Lin L, Song N, Zhang Y, Gao T (2018) Population genetics of Pampus echinogaster along the Pacific coastline of China: insights from the mitochondrial DNA control region and microsatellite molecular markers. Marine and Freshwater Research 69: 971-981. https:// doi.org/10.1071/MF17218

Li Y, Song N, Khan FS, Yanagimoto T, Gao T (2013) New evidence of morphological characters and DNA barcoding of Pampus argenteus (Euphrasen, 1788). Journal of Fisheries of China 37: 1601-1608. https://doi.org/10.3724/SP.J.1231.2013.38824

Li Y, Zhang Y, Gao T, Han Z, Lin L, Zhang X (2017a) Morphological characteristics and DNA barcoding of Pampus echinogaster (Basilewsky, 1855). Acta Oceanologica Sinica 36: 18-23. https://doi.org/10.1007/s13131-017-1124-x

Li Y, Zhang Y, Lin L, Gao T, Liu L (2017b) New genetic perspectives of the ambiguous pomfret as revealed by CR sequences. ZooKeys 719: 59-73. https://doi.org/10.3897/zookeys.719.19914

Li Y, Liu J (2018) Structure selector: A web based software to select and visualize the optimal number of clusters using multiple methods. Molecular Ecology Resources 18: 176-177. https://doi.org/10.1111/1755-0998.12719

Liu J, Li C (1998) Redescription of a stromateoid fish Pampus punctatissimus and comparison with Pampus argenteus from Chinese coastal waters. Chinese Journal of Oceanology and Limnology 16: 161-166. https://doi.org/10.1007/BF02845182

Luikart G, Allendorf FW, Sherwin B, Cornuet JM (1998) Distortion of allele frequency distributions provides a test for recent population bottlenecks. Journal of Heredity 12: 238247. https://doi.org/10.1093/jhered/89.3.238

Meng Y, Zhang L, Zhao F, Shi Z, Zhuang P (2012) Prelimary study on the genetic diversity of four geographic populations of silver pomfret (Pampus argenteus). Marine Fishery 37: 48-52. 
Morgan GR (1985) Stock assessment of the pomfret (Pampus argenteus) in Kuwaiti waters. ICES Journal of Marine Science 42: 3-10. https://doi.org/10.1093/icesjms/42.1.3

Nakabo T (2013) Stromateidae. In: Nakabo T (Ed.) Fishes of Japan with Pictorial Keys to the Species, Third Edition. Kanagawa: Tokai University Press, 1079-1080.

Narges A, Preeta K, Jasem M, Gholam-reza E, Vahid Y (2011) Stock assessment of silver pomfret Pampus argenteus (Euphrasen, 1788) in the Northern Persian Gulf. Turkish Journal of Fisheries and Aquatic Sciences 11: 63-65. https://doi.org/10.4194/trjfas.2011.0109

Ovenden JR, Morgan J, Kashiwagi T, Broderick D, Salini J (2010) Towards better management of Australia's shark fishery: genetic analyses reveal unexpected ratios of cryptic blacktip species Carcharhinus tilstoni and C. limbatus. Marine and Freshwater Research 61: 253-262. https://doi.org/10.1071/MF09151

Page RDM (1996) TREEVIEW: an application to display phylogenetic trees on personal computers. Computer Applications in the Biosciences Cabios 12: 357-358.

Palumbi SR (1994) Genetic divergence, reproductive isolation, and marine speciation. Annual Review of Ecology and Systematics 25: 547-572. https://doi.org/10.1146/annurev. es.25.110194.002555

Peng S, Shi Z, Hou J (2010a) Comparative analysis on the genetic diversity of cultured and wild silver pomfret populations based on mtD-loop and COI gene. Journal of Fisheries of China 34: 19-25. https://doi.org/10.3724/SP.J.1231.2010.06384

Peng S, Shi Z, Chen C, Hou J (2010b) Genetic diversity analysis of silver pomfret (Pampus argenteus) in the East China Sea based on mtDNA D-loop sequence. Marine Science 34: 28-32.

Pillai VN, Menon NG (2000) Marine Fisheries Research and Management. India: Central Marine Fisheries Research Institute, 364-373.

Piper R (2010) Re-occurrence of silver pomfret Pampus argenteus in the North Sea. Marine Biodiversity Record 3: e102. https://doi.org/10.1017/S175526721000093X

Piry S, Luikart G, Cornuet JM (1999) Bottleneck: a computer program for detecting recent reductions in the effective population size using allele frequency data. Journal of Heredity 90: 502-503. https://doi.org/10.1093/jhered/90.4.502

Pritchard JK, Stephens M, Rosenberg NA, Donnelly P (2000) Association mapping in structured populations. American Journal of Human Genetics 67: 170-181. https://doi. org/10.1086/302959

Raymond M, Rousset F (1995) GENEPOP: Population genetics software for exact test and ecumenism. Journal of Heredity 86: 248-249. https://doi.org/10.1093/oxfordjournals. jhered.a111573

Reed DH, Frankham R (2003) Correlation between fitness and genetic diversity. Conservation Biology 17: 230-237. https://doi.org/10.1046/j.1523-1739.2003.01236.x

Sami M, Rym E, Othman J, Hechmi M (2014) First record of Pampus argenteus (Euphrasen, 1788) (Osteichthyes: Stromateidae) in the Tunisian coast (Mediterranean Sea). Journal of Marine Biology and Oceanography 3: 1-2. https://doi.org/10.4172/2324-8661.1000123

Siyal FK, Li Y, Gao T, Liu Q (2013) Maximum sustainable yield estimates of silver pomfret, Pampus argenteus (Family: Strometidae [sic]) fishery in Pakistan. Pakistan Journal of Zoology 45: 447-452. 
Song N, Liu M, Yanagimoto T, Sakurai Y, Han Z, Gao T (2016) Restricted gene flow for Gadus macrocephalus from Yellow Sea based on microsatellite markers: geographic block of Tsushima Current. International Journal of Molecular Science 17: 46. https://doi.org/10.3390/ ijms 17040467

Stepien CA, Karsiotis SI, Sullivan TJ, Klymus KE (2017) Population genetic structure and comparative diversity of smallmouth bass Micropterus dolomieu: congruent patterns from two genomes. Journal of Fish Biology 90: 2125-2147. https://doi.org/10.1111/jfb.13296

Vandewoestijne S, Schtickzelle N, Baguette M (2008) Positive correlation between genetic diversity and fitness in a large, well-connected metapopulation. BMC Biology 6: 46. https:// doi.org/10.1186/1741-7007-6-46

Van Oosterhout C, Hutchinson WF, Wills DPM, Shipley P (2004) MICRO-CHECKER: Software for identifying and correcting genotyping errors in microsatellite data. Molecular Ecology Resource 4: 535-538. https://doi.org/10.1111/j.1471-8286.2004.00684.x

Williams SM, Bennett MB, Pepperell JG, Morgan JAT, Ovenden JR (2015) Spatial genetic subdivision among populations of the highly migratory black marlin Istiompax indica within the central Indo-Pacific. Marine and Freshwater Research 67: 1205-1214. https://doi. org/10.1071/MF14370

Wu R, He X, Zhuang Z, Liu S (2012) Mitochondrial COI sequence variation of silver pomfret (Pampus argenteus) from Chinese coastal waters. Acta Zootaxonomica Sinica 37: 480-488.

Xie S, Watanabe Y (2007) Transport-determined early growth and development of jack mackerel Trachurus japonicus juveniles immigrating into Sagami Bay. Marine and Freshwater Research 58: 1048-1055. https://doi.org/10.1071/MF06165

Yamada U, Tokimura M, Hoshino K, Deng S, Zheng Y, Li S, Kim Y, Kim J (2009) Name and Illustrations of Fish from the East China Sea and the Yellow Sea - Japanese-ChineseKorean - Tokyo. Overseas Fishery Cooperation Foundation of Japan, 525-528.

Yang W, Li J, Yue G (2006) Multiplex genotyping of novel microsatellites from silver pomfret (Pampus argenteus) and cross-amplification in other pomfret species. Molecular Ecology Notes 6: 1073-1075. https://doi.org/10.1111/j.1471-8286.2006.01438.x

Yeh FC, Yang R, Boyle T (1999) POPGENE version 1.32, Microsoft Windows-based freeware for population genetic analysis. University of Alberta and Centre for International Forestry Research, Alberta, Canada.

Zane L, Bargelloni L, Patarnello T (2002) Strategies for microsatellite isolation: a review. Molecular Ecology 11: 1-16. https://doi.org/10.1046/j.0962-1083.2001.01418.x

Zeng L, Cheng Q, Chen X (2012) Microsatellite analysis reveals the population structure and migration patterns of Scomber japonicus (Scombridae) with continuous distribution in the East and South China Seas. Biochemical Systematics and Ecology 42: 83-93. https://doi. org/10.1016/j.bse.2012.02.014

Zhao F, Dong Y, Zhuang P, Zhang T, Zhang L, Shi Z (2011) Genetic diversity of silver pomfret (Pampus argenteus) in the Southern Yellow and East China Seas. Biochemical Systematics and Ecology 39: 145-150. https://doi.org/10.1016/j.bse.2011.02.002

Zhao F, Shi Z, Zhuang P (2010) Advances on reproductive biology and artifcial breeding technology of silver pomfret, Pampus argenteus. Marine Science 34: 90-96. 